\title{
Luminal Domain of ATF6 Alone Is Sufficient for Sensing Endoplasmic Reticulum Stress and Subsequent Transport to the Golgi Apparatus
}

\author{
Yoshimi Sato ${ }^{1}$, Satomi Nadanaka ${ }^{1 \#}$, Tetsuya Okada ${ }^{1}$, Katsuya Okawa ${ }^{2}$, and Kazutoshi Mori ${ }^{*}$ \\ ${ }^{1}$ Department of Biophysics, Graduate School of Science, Kyoto University, Kyoto 606-8502, Japan, ${ }^{2}$ Drug \\ Discovery Research Laboratories, Kyowa Hakko Kirin Co., Ltd., Sunto-gun 411-8731, Japan
}

\begin{abstract}
$A B S T R A C T$. The transcription factor ATF6 is constitutively synthesized as a type II transmembrane protein embedded in the endoplasmic reticulum (ER). When unfolded proteins accumulate in the ER, ATF6 senses such ER stress via an as yet undetermined mechanism and relocates to the Golgi apparatus where it is cleaved by sequential action of Site-1 and Site-2 proteases, allowing liberated N-terminal fragments to translocate into the nucleus. This ATF6-mediated transcriptional induction of ER-localized molecular chaperones and folding enzymes together with components of ER-associated degradation leads to the maintenance of ER homeostasis in mammals. Here, we demonstrated that the luminal domain of ATF6 alone is sufficient for sensing ER stress and subsequent transportation to the Golgi apparatus. This domain of ATF6 was inserted between the N-terminal signal sequence and C-terminal tandem affinity purification tag. The resulting ATF6(C)-TAP translocated into the ER, where it was glycosylated and disulfide bonded. ATF6(C)-TAP occurred as monomer and dimer, and exhibited a relatively short half-life, similar to full-length ATF6. On application of dithiothreitol- or thapsigargininduced ER stress, the ER chaperone BiP dissociated from ATF6(C)-TAP, and ATF6(C)-TAP was transported to the Golgi apparatus and then secreted into medium. Calnexin and protein disulfide isomerase were identified as cellular proteins capable of binding to $\mathrm{ATF6}(\mathrm{C})$-TAP in addition to $\mathrm{BiP}$, and subsequent analysis revealed that protein disulfide isomerase was bound to ATF6(C)-TAP with chaperone activity. These findings indicate that ATF6(C)-TAP can be used as a tool to isolate protein(s) that escort ATF6 from the ER to the Golgi apparatus in response to $\mathrm{ER}$ stress.
\end{abstract}

Key words: endoplasmic reticulum stress/unfolded protein response/protein folding/transcription factor/disulfide bond

\section{Introduction}

When unfolded proteins accumulate in the endoplasmic reticulum (ER), where newly synthesized secretory and transmembrane proteins are folded and assembled, under

\footnotetext{
*To whom correspondence should be addressed: Kazutoshi Mori, Department of Biophysics, Graduate School of Science, Kyoto University, Kitashirakawa-Oiwake, Sakyo-ku, Kyoto 606-8502, Japan.

Tel: +81-75-753-4067, Fax: +81-75-753-3718

E-mail: kazu.mori@bio.mbox.media.kyoto-u.ac.jp

\#Current address: Department of Biochemistry, Kobe Pharmaceutical University, Kobe 658-8558, Japan.

Abbreviations: AMS, 4-acetamido-4'-maleimidylstilbene-2,2'-disulphonic acid; bZIP, basic leucine zipper; ER, endoplasmic reticulum; ERAD, ER-associated degradation; ERSE, ER stress response element; HA, hemagglutinin; IgG bd, immunoglobulin G-binding domain; MEFs, mouse embryonic fibroblasts; NEM, N-ethylmaleimide; PAGE, polyacrylamide gel electrophoresis; PDI, protein disulfide isomerase; SREBP, sterol regulatory element-binding protein; SCAP, SREBP cleavage-activating protein; TAP, tandem affinity purification; TEV, tobacco etch virus; UPR, unfolded protein response; UPRE, UPR element.
}

so-called ER stress conditions, eukaryotic cells activate translational and transcriptional programs collectively termed the unfolded protein response (UPR) to maintain the homeostasis of the ER (Mori, 2000; Ron and Walter, 2007). Major targets of these transcriptional programs are ER-localized molecular chaperones and folding enzymes (collectively termed ER chaperones hereafter) and components of ER-associated degradation (ERAD) machinery. By inducing these proteins, the cell can augment its productive folding and ERAD capacity, both of which are critical for ensuring quality control of proteins in the ER.

Three types of UPR transducers (IRE1, PERK, and ATF6) are ubiquitously expressed in the ER of metazoans. ATF6 is an evolutionarily conserved basic leucine zipper (bZIP) protein. Its function and activation mechanism have been well characterized in mammals, which express closely related ATF6 $\alpha$ and ATF6 $\beta$. ATF6 $\alpha / \beta$ are synthesized as type II transmembrane proteins in the ER, designated pATF $6 \alpha / \beta(\mathrm{P})$, with their bZIP domains facing the cytoplasm 
(Haze et al., 2001, 1999). ATF6 $\alpha / \beta$ sense ER stress by an as yet undetermined mechanism and subsequently translocate to the Golgi apparatus, where they are cleaved by sequential action of Site-1 and Site-2 proteases (Okada et al., 2003; Shen et al., 2002; Ye et al., 2000). The resulting N-terminal fragments liberated from the membrane, designated pATF $6 \alpha / \beta(N)$, enter the nucleus and activate the transcription of their target genes by binding to ER stress-responsive cis-acting elements such as the ER stress response element (ERSE), ERSE II, UPR element (UPRE), and UPRE II (Yoshida et al., 1998, 2000, 2001b). The homodimer of pATF $6 \alpha(\mathrm{N})$ or pATF $6 \beta(\mathrm{N})$ cooperates with the general transcription factor NF-Y to bind to ERSE and ERSE II, whereas ATF6 heterodimerizes with XBP1, a bZIP transcription factor downstream of IRE1, to bind to ERSE II, UPRE, and UPRE II (Yamamoto et al., 2008, 2004; Yoshida et al., 2001a).

Ectopic expression of pATF $6 \alpha(\mathrm{N})$ at a physiologically producible level is sufficient to induce the transcription of ER chaperones (Okada et al., 2002). ATF6 $\alpha$ and ATF6 $\beta$ knock out mice have been developed and characterized (Wu et al., 2007; Yamamoto et al., 2007). Analysis of mouse embryonic fibroblasts (MEFs) deficient in ATF6 $\alpha$ or ATF6 $\beta$ revealed that ATF6 $\alpha$ but not ATF6 $\beta$ is required for transcriptional induction of ER chaperones and ERAD components, and accordingly, mouse embryonic fibroblasts deficient in ATF6 $\alpha$ are sensitive to ER stress. Although mice deficient in ATF6 $\alpha$ or ATF6 $\beta$ are viable and fertile under normal growth conditions, ATF $6 \alpha / \beta$ double knockout results in embryonic lethality, indicating their overlapping function (Yamamoto et al., 2007). Liver steatosis and lipid droplet formation is induced when mice deficient in ATF6 $\alpha$ but not ATF6 $\beta$ are pharmacologically burdened with ER stress (Rutkowski et al., 2008; Yamamoto et al., 2010), Based on these previous findings, we chose to use ATF $6 \alpha$ as a representative of ATF $6 \alpha / \beta$.

Transcriptional control in the UPR begins with sensing protein folding stress in the ER and culminates in transcriptional enhancement of UPR target genes. Remarkably, ATF6 is involved in all steps in this process, as described above. However, while the processes after cleavage at the Golgi apparatus have been well defined, the mechanism by which ATF6 senses ER stress and translocates to the Golgi apparatus is still poorly understood. In a previous study, we showed that the quality control system in the ER operates normally even under ER stress conditions, indicating that ATF6 is differentiated from unfolded or misfolded proteins retained in the ER, and then transported to the Golgi apparatus via COP II vesicles (Nadanaka et al., 2004). Under normal conditions, the major ER chaperone BiP binds to and thus retains ATF6 in the ER. BiP dissociates from ATF6 only under ER stress, thereby allowing transport of ATF6 to the Golgi apparatus (Shen et al., 2002). However, whether or not BiP is the only protein anchoring ATF6 in this manner is unknown, and no escort protein for ATF6 has yet been identified.

We previously found that ATF6 occurs as monomer, dimer, and oligomer forms under normal conditions due to the presence of intra- and intermolecular disulfide bridges formed between the two conserved cysteine residues in the luminal domain. On induction of ER stress not only by the reducing reagent dithiothreitol but also by the glycosylation inhibitor tunicamycin, ER calcium pump inhibitor thapsigargin or glucose starvation, disulfide-bonded ATF6 is reduced, and only this reduced monomer form of ATF6 reaches the Golgi apparatus. Because the reduced monomer form is a better substrate for Site-1 protease than disulfidebonded forms, this mechanism is thought to ensure strict regulation, as the cell can only process ATF6 which has experienced the changes in the ER (Nadanaka et al., 2007, 2006).

Because ER stress-induced changes, such as BiP dissociation and reduction of disulfide bonds, have been found to be associated only with the luminal domain of ATF6, we investigated whether the luminal domain of ATF6 alone is sufficient for sensing ER stress and subsequent transportation to the Golgi apparatus.

\section{Experimental Procedures}

\section{Cell culture and transfection}

HeLa and HEK293 cells as well as ATF6 $\alpha+/+$ and -/MEFs (Yamamoto et al., 2007) were cultured in Dulbecco's modified Eagle's medium (glucose $4.5 \mathrm{~g} /$ liter) supplemented with $10 \%$ fetal bovine serum, $2 \mathrm{mM}$ glutamine, and antibiotics $(100 \mathrm{U} / \mathrm{ml}$ penicillin and $100 \mu \mathrm{g} / \mathrm{ml}$ streptomycin) at $37^{\circ} \mathrm{C}$ in a humidified $5 \% \mathrm{CO}_{2} / 95 \%$ air atmosphere. Transfection was performed using FuGENE6 (Roche) and Lipofectamine 2000 (Invitrogen) according to the manufacturers' instructions.

\section{Construction of plasmids}

Recombinant DNA techniques were performed according to standard procedures (Sambrook et al., 1989) and the integrity of all constructed plasmids was confirmed by extensive sequencing analyses. pCGN-HA-ATF6 $\alpha$ expressing fulllength ATF6 $\alpha$ tagged with the hemagglutinin (HA) epitope at the $\mathrm{N}$ terminus was the kind gift of R. Prywes (Columbia University, New York, NY). pCGN-HA-ATF6 $\alpha(C 467 \mathrm{~A})$, pCGN-HA-ATF6 $\alpha(\mathrm{C} 618 \mathrm{~A})$, and pCGN-HA-ATF6 $\alpha(\mathrm{C} 467$ \&618A) were constructed in a previous study (Nadanaka et al., 2007). pcDNA-ssATF6 $\alpha(\mathrm{C}) \mathrm{WT}-\mathrm{TAP}$ was constructed as follows. Synthetic double-stranded oligonucleotides encoding three tandem copies of c-myc epitope were inserted between the EcoRI and XbaI sites of pcDNA3.1(+) (Invitrogen) to create pcDNA-3xc-myc. Two tandem copies of Immunoglobulin G-binding domain (IgG bd) derived from 
Staphylococcus aureus Protein A were amplified by PCR from pEZZ18 (GE Healthcare Biosciences) with a pair of 5 '-primer carrying the XbaI site and the tobacco etch virus (TEV) protease recognition site, and 3'-primer carrying the ApaI site. To create pcDNA-TAP, an amplified fragment was inserted between the $\mathrm{XbaI}$ and ApaI sites of pcDNA3xc-myc after digestion with XbaI and ApaI. The 405-670 amino acid region of ATF $6 \alpha$ was amplified by PCR from pCGN-HA-ATF6 $\alpha$ with a pair of primers (5'-primer carrying HindIII site and 3'-primer carrying EcoRI site). Amplified fragments were inserted between the HindIII and EcoRI sites of pcDNA-TAP after digestion with HindIII and EcoRI to create pcDNA-ATF6 $\alpha(\mathrm{C}) \mathrm{WT}-\mathrm{TAP}$. pSecTag2A (Invitrogen) was digested with NheI and HindIII to obtain a fragment encoding the Immunoglobulin $\kappa$ leader sequence, which was inserted between the NheI and HindIII sites of pcDNA-ATF6 $\alpha(\mathrm{C}) \mathrm{WT}$-TAP to create pcDNA-ssATF6 $\alpha(\mathrm{C}) \mathrm{WT}$-TAP. pcDNA-ssATF6 $\alpha(\mathrm{C}) \mathrm{C} 467 \mathrm{~A}-$ TAP, pcDNA-ssATF6 $\alpha(\mathrm{C}) \mathrm{C} 618 \mathrm{~A}-\mathrm{TAP}$, and pcDNAssATF6 $\alpha(\mathrm{C}) \mathrm{C} 467 \& 618 \mathrm{~A}-\mathrm{TAP}$ were constructed in a similar manner.

\section{Immunological techniques}

Immunoblotting analysis was carried out according to the standard procedure (Sambrook et al., 1989) as described previously (Okada et al., 2002) using Western Blotting Luminol Reagent (Santa Cruz Biotechnology). Chemiluminescence was detected using an LAS-3000mini LuminoImage analyzer (Fuji Film). Mouse anti-c-myc epitope monoclonal antibody (9E10), mouse anti-HA epitope monoclonal antibody, and rabbit anti-calnexin polyclonal antibody were purchased from Santa Cruz Biotechnology. Mouse anti-KDEL monoclonal and anti-Hsp70 monoclonal antibodies were obtained from Stressgen. Anti-GM130 monoclonal antibody was obtained from BD Bioscience. Anti-ATF6 $\alpha$ polyclonal antibody was obtained as described previously (Haze et al., 1999), and anti-protein disulfide isomerase (PDI) polyclonal antibody is a kind gift of Masakazu Kikuchi (Ritsumeikan University, Otsu, Japan).

To assess indirect immunofluorescence, cells were first fixed with $3.7 \%$ formaldehyde for $10 \mathrm{~min}$ and permeabilized with $0.2 \%$ Triton X-100 in PBS for 10 min. Cells were then reacted with rabbit anti-c-myc epitope polyclonal antibody (Medical \& Biological Laboratories) and mouse anti-GM130 monoclonal antibody for $1 \mathrm{~h}$ and incubated with FITC-conjugated anti-rabbit IgG antibody (MP Biomedicals) or rhodamine-conjugated anti-mouse IgG antibody (Cappel) for $1 \mathrm{~h}$ at room temperature. Fluorescence was visualized using a Leica TCS SP2 confocal microscope system (400-mW Ar/Kr 457- to 675-nm laser, Leica DM IRE2 fluorescence microscope, $63 \times 1.40$ - to 0.60 -numerical aperture HCXPLAPO oil objective).

Immunoprecipitation was carried out as described previously (Nadanaka et al., 2007).

\section{Tandem affinity purification (TAP)}

HEK293 cells were harvested in PBS containing $10 \mathrm{mM}$ NEM, suspended in $0.01 \%$ digitonin buffer [50 mM Tris/ $\mathrm{HCl}$ buffer, $\mathrm{pH} 8.0$, containing $150 \mathrm{mM} \mathrm{NaCl}, 10 \mathrm{mM}$ NEM, $0.01 \%$ digitonin (Wako), protease inhibiter cocktail, and $10 \mu \mathrm{M}$ MG132], left on ice for $8 \mathrm{~min}$, and then centrifuged at $14,000 \mathrm{rpm}$ for $15 \mathrm{~min}$ at $4^{\circ} \mathrm{C}$. The resulting supernatant was discarded, and the pellet was washed with PBS, resuspended in $1 \%$ digitonin buffer $[50 \mathrm{mM}$ Tris $/ \mathrm{HCl}$ buffer, $\mathrm{pH}$ 8.0, containing $150 \mathrm{mM} \mathrm{NaCl}, 10 \mathrm{mM}$ NEM, 1\% digitonin, $2 \mathrm{mM} \mathrm{ATP}, 2 \mathrm{mM} \mathrm{MgCl}_{2}$, protease inhibiter cocktail, and $10 \mu \mathrm{M}$ MG132], left on ice for $30 \mathrm{~min}$, and centrifuged at $14,000 \mathrm{rpm}$ for $15 \mathrm{~min}$ at $4^{\circ} \mathrm{C}$. The resulting supernatant was incubated with IgG sepharose (GE Healthcare Biosciences) for $4 \mathrm{hr}$ at $4^{\circ} \mathrm{C}$. After brief centrifugation, the supernatant was discarded. The beads were washed three times with $0.1 \%$ digitonin buffer [50 $\mathrm{mM}$ Tris $/ \mathrm{HCl}$ buffer, $\mathrm{pH} 8.0$, containing $0.5 \mathrm{mM}$ EDTA, $0.1 \%$ digitonin, 2 $\mathrm{mM}$ ATP, $\left.2 \mathrm{mM} \mathrm{MgCl}_{2}\right]$ and incubated overnight at $4^{\circ} \mathrm{C}$ with TEV protease (Invitrogen) dissolved in $50 \mathrm{mM}$ Tris/ $\mathrm{HCl}$ buffer, $\mathrm{pH} 8.0$, containing $0.5 \mathrm{mM}$ EDTA and $0.1 \%$ digitonin. Eluted proteins obtained by brief centrifugation were subjected to SDS-polyacrylamide gel electrophoresis (PAGE) and visualized by silver staining.

\section{Mass spectrometry}

Mass spectrometric identification of proteins was performed as previously described (Jensen et al., 1996). Briefly, after SDS-PAGE, proteins were visualized using silver staining and excised separately from gels, followed by in-gel digestion with trypsin (Promega) in buffer containing $50 \mathrm{mM}$ ammonium bicarbonate ( $\mathrm{pH} 8.0$ ) and $2 \%$ acetonitrile overnight at $37^{\circ} \mathrm{C}$. Molecular mass analyses of triptic peptides were performed using matrix-assisted laser desorption/ ionization time-of-flight mass spectrometry (MALDI-TOF/ MS) with an a ultraflex TOF/TOF (Bruker Daltonics). Proteins were identified by comparing the molecular weights determined by MALDI-TOF/MS with theoretical peptide masses from the proteins registered in the NCBInr database.

\section{Modification of free and reactive sulfhydryl groups}

HeLa cells were harvested in ice-cold PBS with or without $10 \mathrm{mM}$ N-ethylmaleimide (NEM, Wako). Cell pellets were lyzed in reaction buffer $(80 \mathrm{mM}$ Tris/ $\mathrm{HCl}$ buffer, $\mathrm{pH} 6.8$, containing $2 \%$ SDS) with or without $5 \mathrm{mM}$ 4-acetamido-4'maleimidylstilbene-2,2'-disulphonic acid (AMS, Molecular Probe), left in the dark for $30 \mathrm{~min}$ on ice and then for another $30 \mathrm{~min}$ at room temperature. The reaction was stopped by boiling for $5 \mathrm{~min}$ after the addition of an equal volume of 2 x Laemmli's sample buffer. 


\section{Enzymatic deglycosylation}

HeLa cells were solubilized in lysis buffer [50 mM Tris/ $\mathrm{HCl}$ buffer, $\mathrm{pH}$ 8.0, containing $150 \mathrm{mM} \mathrm{NaCl}, 1 \% \mathrm{NP}-40$, protease inhibitor cocktail (Nacalai Tesque), and $10 \mu \mathrm{M}$ MG132]. Cell lysates clarified by centrifugation at 14,000 rpm for $15 \mathrm{~min}$ at $4^{\circ} \mathrm{C}$ as well as cultured medium were incubated with mouse anti-c-myc epitope monoclonal antibody (Santa Cruz Biotechnology) for overnight at $4^{\circ} \mathrm{C}$ and then with Protein G sepharose (GE Healthcare Biosciences) for $1-2 \mathrm{hr}$ at $4{ }^{\circ} \mathrm{C}$. Sepharose beads were collected by brief centrifugation and washed three times with lysis buffer. Immunoprecipitated materials were eluted by boiling for 5 min in 1\% SDS solution and re-boiling for $5 \mathrm{~min}$ after the addition of 1/10 volume of 2-mercaptoethanol, and separated from beads by brief centrifugation. Two volumes of $150 \mathrm{mM}$ citrate buffer, $\mathrm{pH} 5.5$, were added to the resulting supernatant. A $10-\mu l$ aliquot of the solution was incubated with $0.4 \mathrm{mIU}$ endoglycosidase H (CALBIOCHEM) in the presence of $0.1 \mu \mathrm{l}$ of protease inhibitor cocktail overnight at $37^{\circ} \mathrm{C}$. Another $10-\mu \mathrm{l}$ aliquot was mixed with $1 \mu \mathrm{l}$ of $0.2 \mathrm{M}$ sodium phosphate buffer, $\mathrm{pH} 7.0,1 \mu \mathrm{l}$ of $0.1 \mathrm{M}$ EDTA and 1 IU peptide- $\mathrm{N}$-glycosidase $\mathrm{F}$ (Roche), and incubated overnight at $37^{\circ} \mathrm{C}$.

\section{Analysis of redox state of PDI}

HEK293 cells were untreated or treated with either $5 \mathrm{mM}$ dithiothreitol for $5 \mathrm{~min}, 5 \mathrm{mM}$ diamide for $5 \mathrm{~min}$, or $300 \mathrm{nM}$ thapsigargin for various periods. Cells were harvested in ice-cold PBS containing 10\% trichloroacetic acid (Nacalai Tesque), left on ice for $1 \mathrm{~h}$, and centrifuged at 14,000 rpm for $15 \mathrm{~min}$ at $4^{\circ} \mathrm{C}$. The resulting supernatant was discarded. The pellet was washed three times with $70 \%$ acetone, dried and resuspended in reaction buffer $(80 \mathrm{mM}$ Tris/ $\mathrm{HCl}, \mathrm{pH}$ 6.8 , containing $2 \%$ SDS) with or without $5 \mathrm{mM}$ AMS (Molecular Probe). The samples were left in the dark for 30 min at room temperature and then for $30 \mathrm{~min}$ at $37^{\circ} \mathrm{C}$. The reaction was stopped by boiling for $5 \mathrm{~min}$ after the addition of an equal volume of $2 \mathrm{x}$ Laemmli's sample buffer.

\section{Results}

\section{Disulfide bond formation in ATF6 luminal domain}

To determine whether or not the luminal domain of ATF6 alone is sufficient for sensing ER stress and subsequent transport to the Golgi apparatus, and to facilitate isolation of ATF6-binding proteins involved in ER stress-induced reduction or transport of ATF6, we inserted the luminal domain of ATF6 $\alpha$ (amino acids 405-670) between the signal sequence of an Immunoglobulin $\kappa$ chain and TAP tag consisting of three tandem copies of c-myc epitope, a TEV protease recognition site, and two tandem copies of
IgG bd derived from Staphylococcus aureus Protein A [ATF $6 \alpha(\mathrm{C})$ WT-TAP, Fig. 1A]. As a control for ER stressinduced reduction, we also inserted a mutant luminal domain with two conserved cysteine residues changed to alanine $[\mathrm{ATF} 6 \alpha(\mathrm{C}) \mathrm{C} 467 \& 618 \mathrm{~A}-\mathrm{TAP}$, Fig. 1A]. Cell lysates were prepared from HeLa cells transfected with these two constructs and subjected to SDS-PAGE under reducing and non-reducing conditions. ATF $6 \alpha(\mathrm{C}) \mathrm{WT}-\mathrm{TAP}$ migrated as a single band under reducing conditions but as multiple bands under non-reducing conditions (Fig. 1B, lanes 1 and 2). In contrast, ATF $6 \alpha(\mathrm{C}) \mathrm{C} 467 \& 618 \mathrm{~A}-\mathrm{TAP}$ migrated as a single band under both reducing and non-reducing conditions, as expected (Fig. 1B, lanes 3 and 4). It should be noted that the TAP tag contains no cysteines.

To assign multiple bands observed for ATF6 $\alpha(\mathrm{C}) \mathrm{WT}$ TAP under non-reducing conditions, we expressed not only ATF $6 \alpha(\mathrm{C})$ WT-TAP and ATF6 $\alpha(\mathrm{C}) \mathrm{C} 467 \& 618 \mathrm{~A}-\mathrm{TAP}$ but also point mutants such as ATF6 $\alpha(\mathrm{C}) \mathrm{C} 467 \mathrm{~A}-\mathrm{TAP}$ and ATF6 $\alpha($ C)C618A-TAP (Fig. 1A) in HeLa cells or HEK293 cells. We previously showed that the C467A mutant of fulllength ATF6 $\alpha$ formed monomer and dimer, as expected, whereas the C618A mutant of full-length ATF6 $\alpha$ formed monomer and oligomer by forming disulfide bonds with putative protein X (Nadanaka et al., 2007). Analysis of the migration positions of ATF $6 \alpha(\mathrm{C}) \mathrm{C} 467 \mathrm{~A}-\mathrm{TAP}$ and ATF6 $\alpha(\mathrm{C}) \mathrm{C} 618 \mathrm{~A}-\mathrm{TAP}$ expressed in HeLa cells (data not shown) or HEK293 cells under non-reducing conditions (Fig. 1C) suggested that the uppermost band represented dimer, whereas the intense bands around $150 \mathrm{kDa}$ represented oligomer and its probable degradation product. However, this assignment would mean that oligomer migrates faster than dimer, which is quite unlikely. It should be noted that similar results were obtained when these four constructs were introduced into wild-type or ATF6 $\alpha$-deficient MEFs (Fig. 1D), indicating that disulfide bonding does not require assistance from endogenous ATF6 $\alpha$.

To identify which protein(s) are components of these disulfide-bonded bands, we purified them using a specific interaction between TAP and IgG sepharose. HEK293 cells expressing ATF6 $\alpha(\mathrm{C})$ WT-TAP, ATF $6 \alpha(\mathrm{C}) \mathrm{C} 467 \mathrm{~A}-\mathrm{TAP}$, ATF6 $\alpha(\mathrm{C}) \mathrm{C} 618 \mathrm{~A}-\mathrm{TAP}$, or ATF6 $\alpha(\mathrm{C}) \mathrm{C} 467 \& 618 \mathrm{~A}-\mathrm{TAP}$ were solubilized with $0.01 \%$ digitonin to remove cytosolic proteins. The pellets left behind were dissolved in 1\% digitonin, and the solubilized proteins were subjected to affinity chromatography using IgG sepharose. Bound proteins were eluted by digestion with TEV protease, subjected to SDSPAGE under non-reducing conditions, and analyzed by immunoblotting using anti-c-myc epitope antibody. As shown in Fig. 2A, essentially all immunoreactive bands were bound to IgG sepharose and eluted by digestion with TEV protease. We noticed that the difference in the migration positions between the uppermost band and the intense bands around $150 \mathrm{kDa}$ became much smaller after the removal of $2 \mathrm{x} \operatorname{IgG} \mathrm{bd}$. Aliquot of the eluates were subjected to SDS-PAGE under non-reducing conditions, and then 

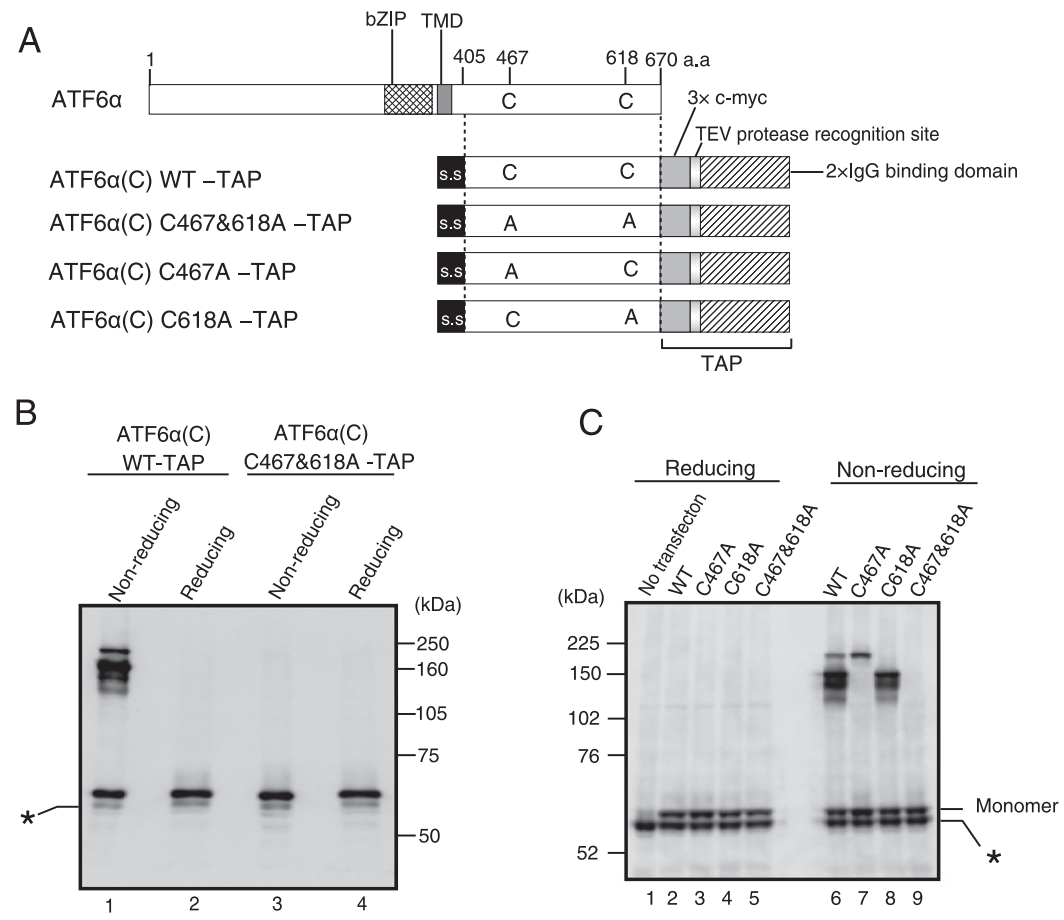

$\mathrm{D}$

ATF $6 \alpha+/+$ MEF ATF6 $\alpha-/-$ MEF

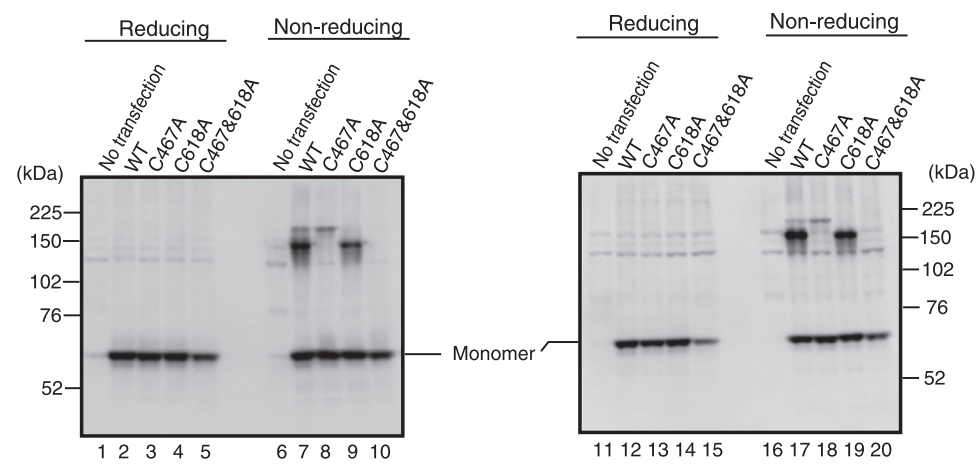

Fig. 1. Disulfide bond formation in ATF6 $\alpha(C)$-TAP. (A) Domain structure of ATF6 $\alpha$ and schematic presentation of fusion proteins used for analysis. ATF6 $\alpha$ contains the bZIP domain and transmembrane domain (TMD). The ATF6 luminal domain contains two conserved cysteine residues (Cys467 and Cys618). A signal sequence (s.s.) of Immunoglobulin $\kappa$ chain and TAP tag consisting of three tandem copies of c-myc epitope, a TEV protease recognition site and two tandem copies of IgG bd derived from Protein A were attached to the N- and C-termini of the luminal domain of ATF6 $\alpha$ (amino acids 405$670)$, respectively, to create ATF $6 \alpha(\mathrm{C}) \mathrm{WT}-\mathrm{TAP}$. The two conserved cysteine residues in ATF6 $\alpha(\mathrm{C}) \mathrm{WT}-\mathrm{TAP}$ were mutated to alanine to create ATF6 $\alpha(C)$ C467\&618A-TAP, ATF6 $\alpha(C)$ C467A-TAP, or ATF6 $\alpha(C)$ C618A-TAP. (B) HeLa cells transfected with a plasmid to express ATF6 $\alpha(C)$ WT-TAP or ATF6 $\alpha(\mathrm{C}) \mathrm{C} 467 \& 618 \mathrm{~A}$-TAP were lyzed in $10 \mathrm{mM}$ NEM-containing Laemmli's sample buffer without reducing reagent and then boiled for $5 \mathrm{~min}$ in the presence or absence of $100 \mathrm{mM}$ dithiothreitol for the analysis under reducing or non-reducing conditions, respectively. Resulting cell lysates were analyzed by immunoblotting using anti-c-myc epitope antibody. Migration positions of molecular weight markers (GE Healthcare Biosciences) are indicated. An asterisk denotes a non-specific band, which was also detected in lysates of untransfected cells (see Fig. 1C, lane 1). (C) HEK293 cells transfected with a plasmid to express ATF6 $\alpha(\mathrm{C})$ WT-TAP, ATF6 $\alpha(\mathrm{C}) \mathrm{C} 467 \mathrm{~A}-\mathrm{TAP}, \mathrm{ATF} 6 \alpha(\mathrm{C}) \mathrm{C618A-TAP}$, or ATF6 $\alpha(\mathrm{C}) \mathrm{C} 467 \& 618 \mathrm{~A}-\mathrm{TAP}$ were analyzed as in B. Migration positions of monomer as well as molecular weight markers are indicated. (D) ATF $6 \alpha+/+$ and $-/-$ MEFs transfected with a plasmid to express ATF6 $\alpha(\mathrm{C})$ WT-TAP, ATF6 $\alpha(\mathrm{C}) \mathrm{C} 467 \mathrm{~A}-\mathrm{TAP}, \mathrm{ATF} 6 \alpha(\mathrm{C}) \mathrm{C} 618 \mathrm{~A}-\mathrm{TAP}$, or ATF6 $\alpha(\mathrm{C}) \mathrm{C} 467 \& 618 \mathrm{~A}-\mathrm{TAP}$ were analyzed as in B.

silver-stained (Fig. 2B). Mass spectrometric analysis identified only ATF6 $\alpha$ as a component of both the uppermost band and the faster-migrating intense bands.

To biochemically determine whether these disulfide- bonded proteins contain free reactive sulfhydryl groups, cell lysates were first treated with NEM (molecular weight: 125) or left untreated, and then treated with AMS (molecular weight: 536) or again left untreated, as schematically shown 
A

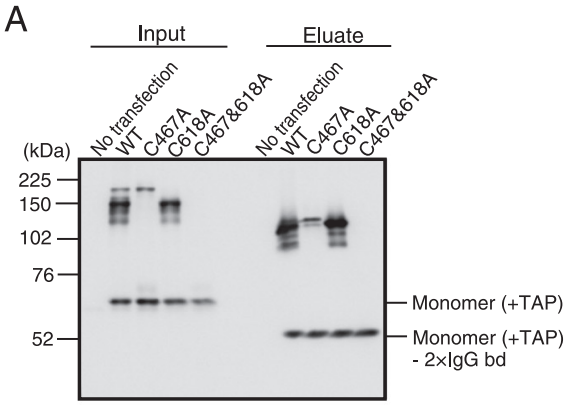

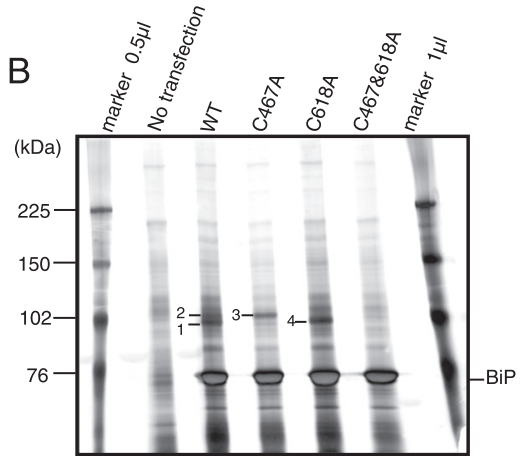

$\operatorname{ATF} 6 a(C)$ C467\&618A -TAP
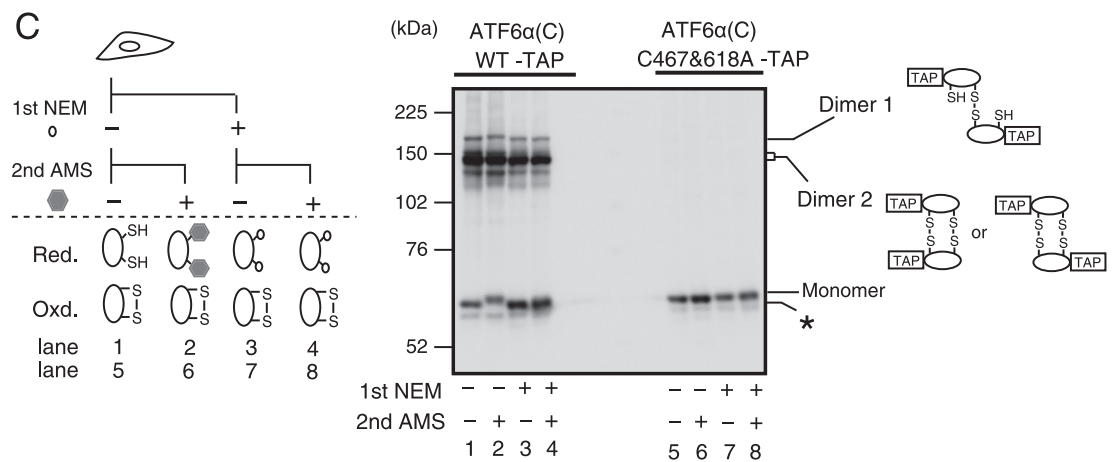

D
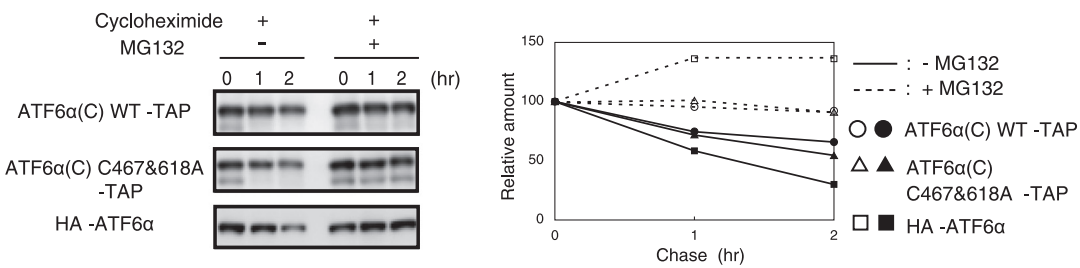

Fig. 2. Characterization of ATF6 $\alpha($ C)-TAP. (A) HEK293 cells transfected with a plasmid to express ATF6 $\alpha(C)$ WT-TAP, ATF6 $\alpha(C) C 467 A-T A P$, ATF6 $\alpha(\mathrm{C}) \mathrm{C} 618 \mathrm{~A}-\mathrm{TAP}$, or ATF6 $\alpha(\mathrm{C}) \mathrm{C} 467 \& 618 \mathrm{~A}-\mathrm{TAP}$ were subjected to tandem affinity purification as described in Experimental Procedures. Aliquots of materials applied to the IgG sepharose column (Input) and eluate obtained after TEV digestion (Eluate) were subjected to SDS-PAGE under non-reducing conditions and analyzed by immunoblotting using anti-c-myc epitope antibody. Migration positions of monomer (+TAP) and monomer (+TAP)-2xIgG bd are indicated. (B) Eluates obtained as in (A) were subjected to SDS-PAGE under non-reducing conditions and silver-stained. Visualized bands 1-4 were subjected to mass spectrometric analysis as described in Experimental Procedures. (C) HeLa cells transfected with a plasmid to express ATF6 $\alpha(\mathrm{C}) \mathrm{WT}-\mathrm{TAP}$ or ATF6 $\alpha(\mathrm{C}) \mathrm{C} 467 \& 618 \mathrm{~A}-\mathrm{TAP}$ were harvested in PBS with $(+)$ or without $(-) 10 \mathrm{mM} \mathrm{NEM}(1 \mathrm{st}$ NEM) and then lyzed in $2 \%$ SDS with (+) or without $(-) 5$ mM AMS (2nd AMS). Possible modifications of two cysteine residues are shown schematically (left panel). Cell lysates were subjected to SDS-PAGE under non-reducing conditions and analyzed by immunoblotting using anti-c-myc epitope antibody. An asterisk denotes a non-specific band. Conformational differences between dimer 1 and dimer 2 are shown schematically (right panel). (D) HeLa cells transfected with a plasmid to express ATF6 $\alpha(\mathrm{C})$ WT-TAP, ATF6 $\alpha(\mathrm{C}) \mathrm{C} 467 \& 618 \mathrm{~A}$-TAP, or HA-tagged full-length ATF6 $\alpha$ were treated with $5 \mu \mathrm{g} / \mathrm{ml}$ cycloheximide in the presence $(+)$ or absence (-) of $10 \mu \mathrm{M}$ MG132 for the indicated periods. Cell lysates were prepared as in Fig. 1B, subjected to SDS-PAGE under reducing conditions and analyzed by immunoblotting using anti-c-myc or anti-HA epitope antibody (left panel). The intensity of each band was quantified, normalized to a value of $0 \mathrm{~h}$, and plotted against incubation time (right panel).

in Fig. 2C. Due to the difference in molecular weights, AMS-modified proteins are expected to migrate more slowly than NEM-modified or unmodified proteins. Immunoblotting analysis showed that the intense bands of ATF $6 \alpha(\mathrm{C})$ WT-TAP around $150 \mathrm{kDa}$ were not affected by treatment with or without NEM followed by treatment with or without AMS, indicating that they were indeed completely disulfide-bonded (Fig. 2C, compare lanes 1-4). In contrast, the uppermost band of ATF6 $\alpha(\mathrm{C})$ WT-TAP migrated more slowly when cell lysates were not treated with NEM but were treated with AMS, indicating that it contained free cysteines (Fig. 2C, compare lane 2 with lane 1). Based on these results, we concluded that the uppermost band, designated dimer 1 hereafter, contains one disulfide bond and two free cysteines, whereas the intense bands around $150 \mathrm{kDa}$, designated dimer 2 hereafter, contain two 


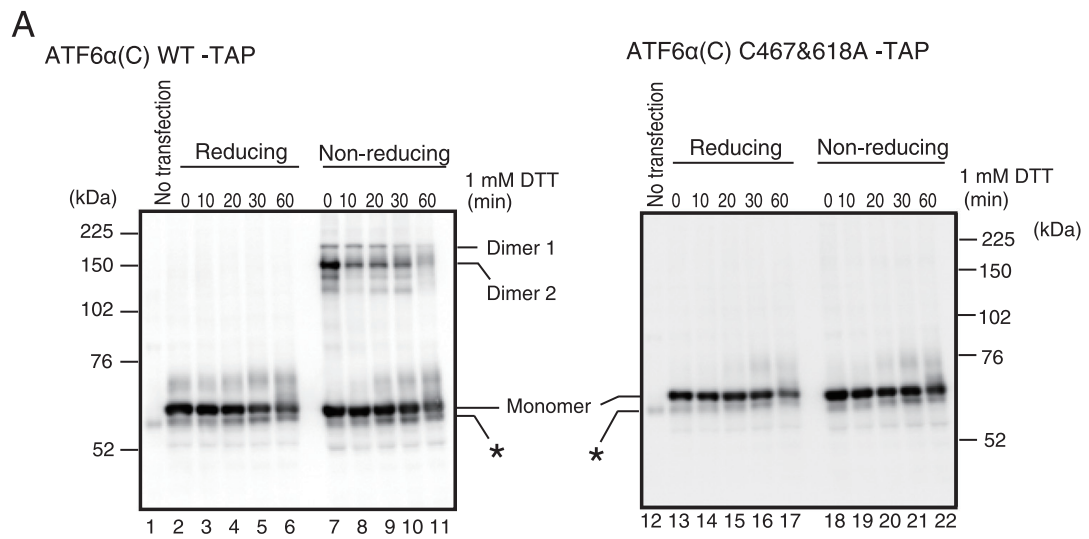

B
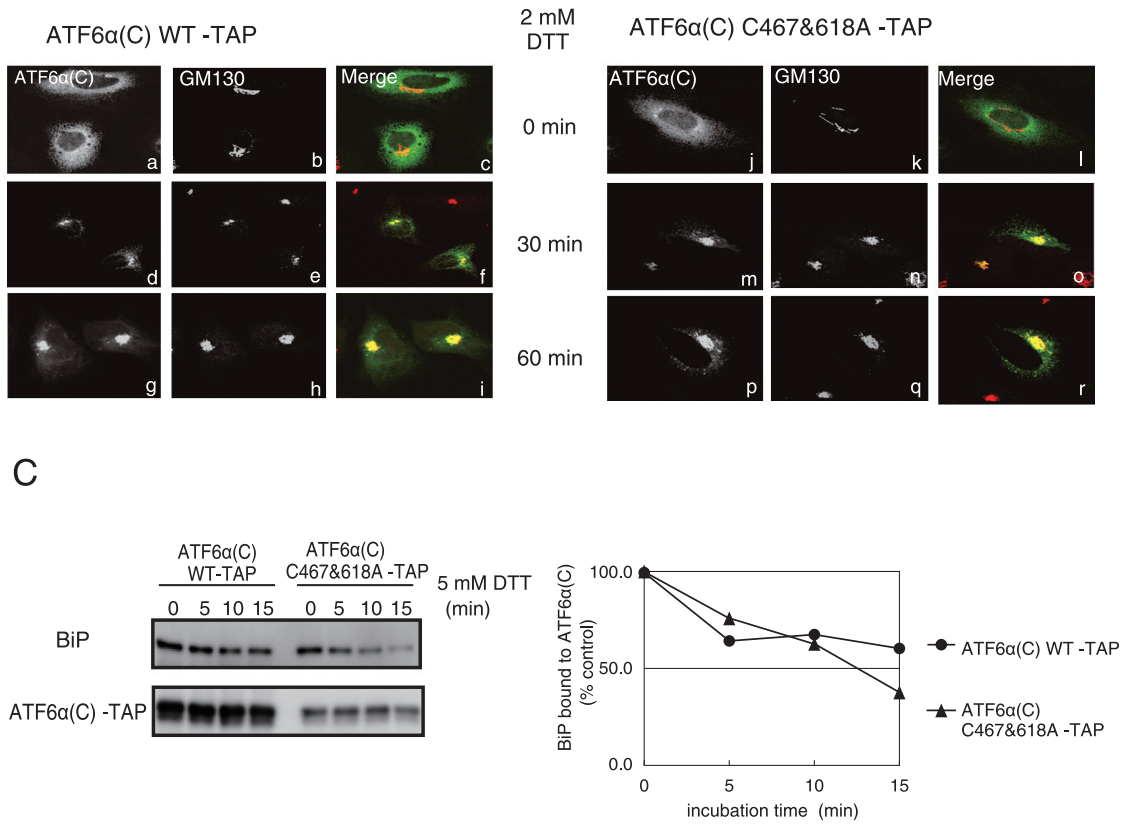

Fig. 3. Dithiothreitol-induced reduction and transport of ATF6 $\alpha(C)$-TAP. (A) HeLa cells transfected with a plasmid to express ATF6 $\alpha(C)$ WT-TAP or ATF $6 \alpha(C) C 467 \& 618 \mathrm{~A}-\mathrm{TAP}$ were treated with $1 \mathrm{mM}$ dithiothreitol (DTT) for the indicated periods. Cell lysates were prepared and analyzed as in Fig. 1B. (B) HeLa cells transfected with a plasmid to express ATF6 $\alpha(\mathrm{C})$ WT-TAP or TF $6 \alpha(\mathrm{C}) \mathrm{C} 467 \& 618 \mathrm{~A}-\mathrm{TAP}$ were treated with $2 \mathrm{mM}$ DTT for the indicated periods. Cells were fixed, immunostained with anti-c-myc epitope or anti-GM130 antibody, and analyzed using confocal fluorescence microscopy. (C) HeLa cells transfected with a plasmid to express ATF6 $\alpha(\mathrm{C})$ WT-TAP or ATF6 $\alpha(\mathrm{C}) \mathrm{C} 467 \& 618 \mathrm{~A}-\mathrm{TAP}$ were treated with $5 \mathrm{mM}$ DTT for the indicated periods. Cell lysates were prepared and subjected to immunoprecipitation using anti-c-myc epitope antibody as described in EXPERIMENTAL PROCEDURES. The immunoprecipitated materials were analyzed by immunoblotting with anti-c-myc epitope and anti-KDEL antibodies (left panel). The intensity of each band was quantified, normalized to a value of $0 \mathrm{~h}$, and plotted against incubation time (right panel).

disulfide bonds. These are thus all dimers with different conformations, as schematically shown in Fig. 2C.

Furthermore, we noticed that the monomer band of ATF $6 \alpha(\mathrm{C})$ WT-TAP also migrated more slowly when cell lysates were not treated with NEM but were treated with AMS, indicating that it was not disulfide-bonded intramolecularly (Fig. 2C, compare lane 2 with lane 1), in contrast to observations made with endogenous monomer ATF6 $\alpha$ (Nadanaka et al., 2007). Disulfide bond formation in mono- mer appears to have been blocked by conformational restriction caused by attachment of the TAP tag. In contrast, the monomer band of ATF $6 \alpha(\mathrm{C}) \mathrm{C} 467 \& 618 \mathrm{~A}-\mathrm{TAP}$ was not affected by treatment with or without NEM followed by treatment with or without AMS, as expected (Fig. 2C, lanes 5-8). Immunofluorescence analysis revealed that both ATF6 $\alpha(\mathrm{C})$ WT-TAP and ATF6 $\alpha(\mathrm{C}) \mathrm{C} 467 \& 618 \mathrm{~A}-\mathrm{TAP}$ were localized exclusively in the ER under normal conditions (Fig. 3B, panels a-c and j-1; Fig. 4B, panels $\mathrm{a}-\mathrm{c}$ and $\mathrm{j}-1$ ), 
A

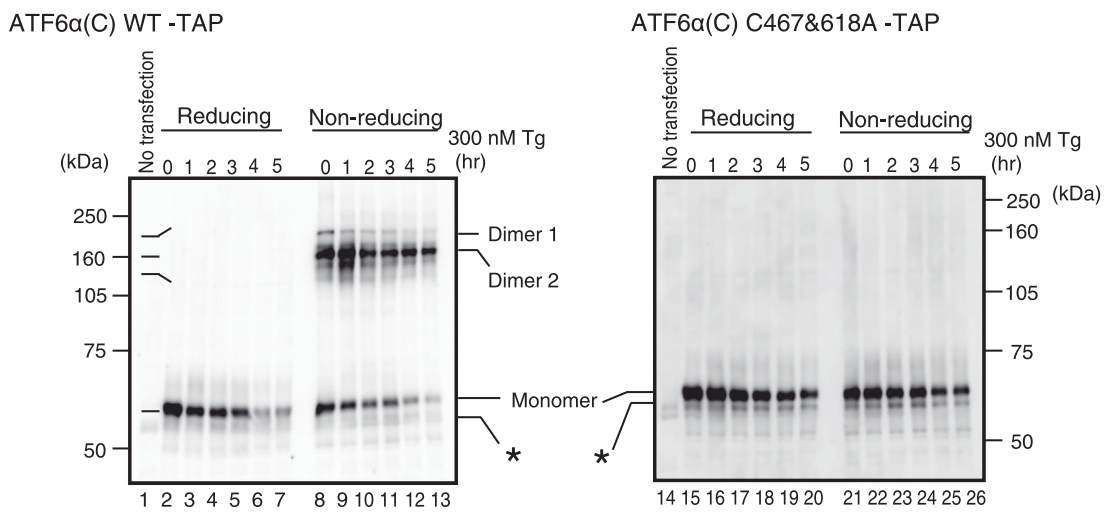

B

ATF6a(C) WT -TAP
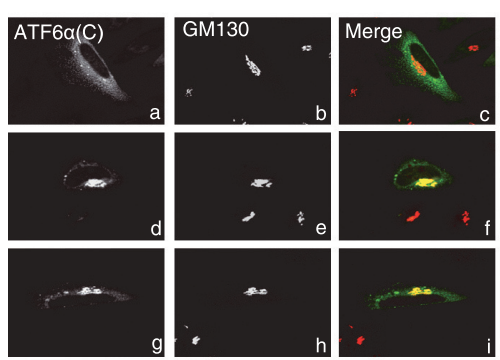

$300 \mathrm{nM} \quad$ ATF6 $\alpha(C)$ C467\&618A -TAP

$\mathrm{Tg}$
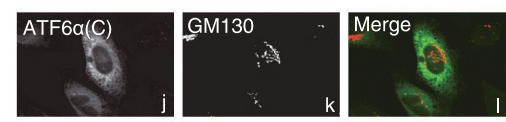

$3 \mathrm{hr}$
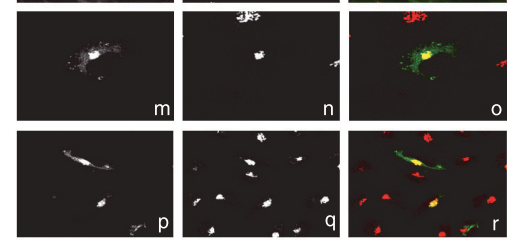

C

ATF6a(C) WT -TAP

ATF6a(C) C467\&618A -TAP
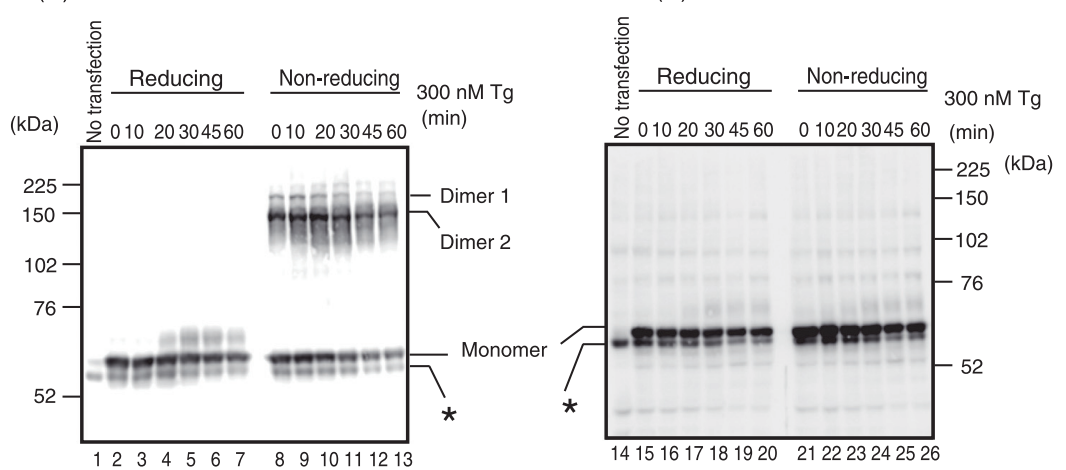

Fig. 4. Thapsigargin-induced reduction and transport of ATF6 $\alpha(\mathrm{C})$-TAP. (A) HeLa cells transfected with a plasmid to express ATF6 $\alpha(\mathrm{C}) \mathrm{WT}-\mathrm{TAP}$ or ATF $6 \alpha(C)$ C467\&618A-TAP were treated with $300 \mathrm{nM}$ thapsigargin $(\mathrm{Tg})$ for the indicated periods. Cell lysates were prepared and analyzed as in Fig. 1B. (B) HeLa cells transfected with a plasmid to express ATF6 $\alpha(\mathrm{C}) \mathrm{WT}-\mathrm{TAP}$ or ATF $6 \alpha(\mathrm{C}) \mathrm{C} 467 \& 618 \mathrm{~A}$-TAP were treated with $300 \mathrm{nM}$ Tg for the indicated periods. Cells were fixed, immunostained with anti-c-myc epitope or anti-GM130 antibody, and analyzed using confocal fluorescence microscopy. (C) HeLa cells transfected with a plasmid to express ATF6 $\alpha(\mathrm{C})$ WT-TAP or ATF6 $\alpha(\mathrm{C}) \mathrm{C} 467 \& 618 \mathrm{~A}-\mathrm{TAP}$ were treated with $300 \mathrm{nM}$ thapsigargin $(\mathrm{Tg})$ for the indicated periods. Cell lysates were prepared and analyzed as in Fig. 1B.

consistent with our previous notion that reduction is not sufficient to activate ATF6 $\alpha$ (Nadanaka et al., 2007).

Cycloheximide chase experiments showed that both ATF6 $\alpha(C)$ WT-TAP and ATF6 $\alpha(C) C 467 \& 618 A-T A P$ turned over with a half-life of approximately $2 \mathrm{~h}$, a value being comparable to the short half-life of HA-tagged fulllength ATF6 $\alpha$, and that MG132 treatment blocked this degradation
(Fig. 2D). These results indicate that newly synthesized ATF6 $\alpha(\mathrm{C})$ WT-TAP and ATF6 $\alpha(\mathrm{C}) \mathrm{C} 467 \& 618 \mathrm{~A}-\mathrm{TAP}$ are translocated into the lumen of the ER where oxidative folding and N-linked glycosylation occur (evidence of glycosylation presented in sections below), and are then constitutively retrotranslocated back to the cytosol to be degraded by the proteasome, even under normal conditions. 


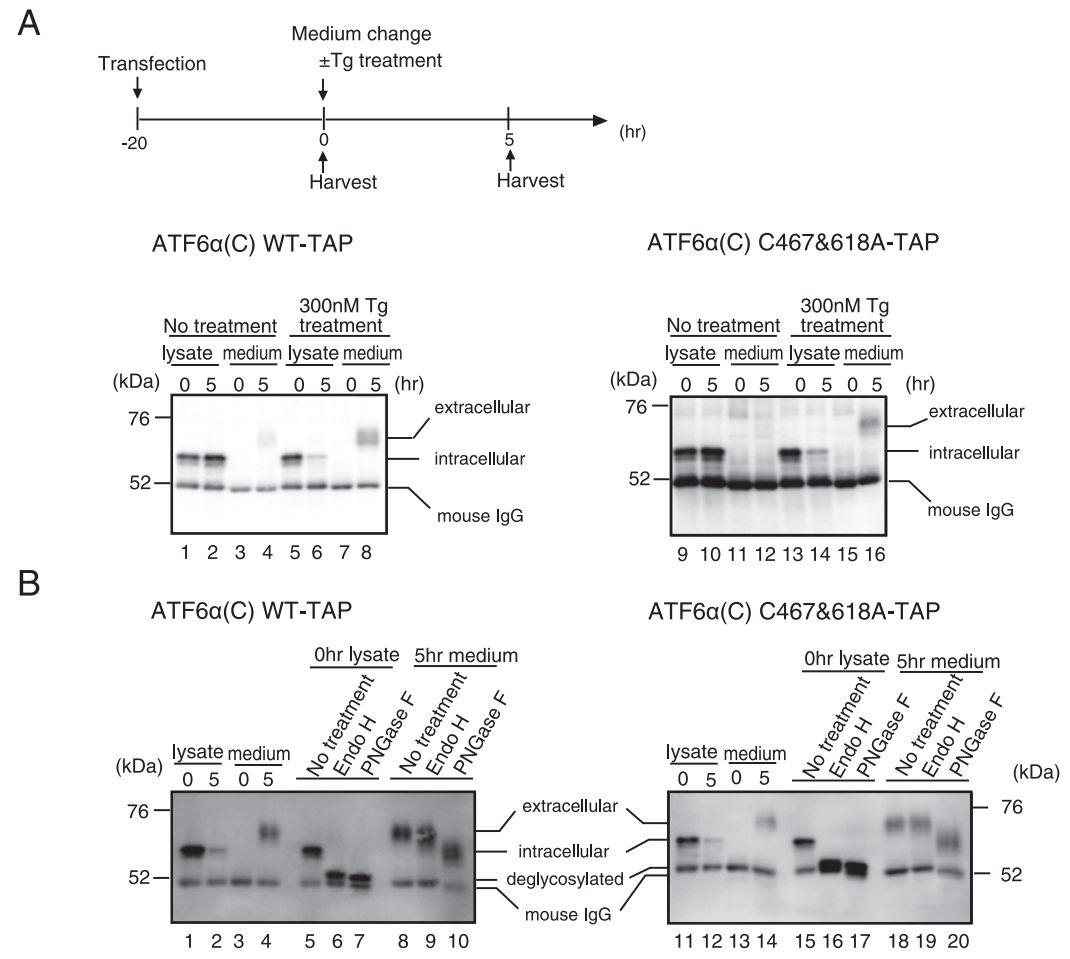

Fig. 5. Thapsigargin-induced secretion of ATF6 $\alpha$ (C)-TAP. (A) HeLa cells were transfected with a plasmid to express ATF6 $\alpha$ (C)WT-TAP or ATF $6 \alpha(\mathrm{C}) \mathrm{C} 467 \& 618 \mathrm{~A}-\mathrm{TAP}$. Twenty hours later, culture medium was exchanged for fresh medium with or without $300 \mathrm{nM}$ thapsigargin (Tg), and cells were incubated further for $5 \mathrm{hr}$, as shown schematically at the top of the figure. Cells and medium at 0 and $5 \mathrm{hr}$ after the medium change were subjected to immunoprecipitation using anti-c-myc epitope antibody as described in EXPERIMENTAL PROCEDURES. Immunoprecipitated materials were subjected to SDS-PAGE under reducing conditions and analyzed by immunoblotting using anti-c-myc epitope antibody. Migration positions of extracellular and intracellular ATF6 $\alpha(\mathrm{C})$-TAP as well as mouse IgG are indicated. (B) Aliquots of immunoprecipitated proteins prepared as in A from cell lysates at $0 \mathrm{~h}$ and medium at $5 \mathrm{~h}$ after the addition of thapsigargin were left untreated or treated with endoglycosidase $\mathrm{H}$ (Endo $\mathrm{H}$ ) or peptide-N-glycosidase $\mathrm{F}$ (PNGase $\mathrm{F}$ ) prior to SDS-PAGE as indicated. Migration positions of intracellular and extracellular forms of ATF6 $\alpha(\mathrm{C})$-TAP as well as deglycosylated ATF6 $\alpha(\mathrm{C})$-TAP and mouse IgG are indicated.

\section{ER stress-induced reduction, BiP dissociation, and transport of ATF6 luminal domain}

We examined whether the TAP-tagged ATF6 luminal domain is reduced and transported to the Golgi apparatus in response to ER stress, as in the case of endogenous ATF6 $\alpha$. After treatment of HeLa cells with dithiothreitol, which is known to be the most effective activator of ATF6 among ER stress inducers (Haze et al., 1999), levels of dimer 1 and dimer 2 of ATF $6 \alpha(\mathrm{C}) \mathrm{WT}-\mathrm{TAP}$ were decreased (Fig. 3A, lanes 7-11), and ATF6 $\alpha(\mathrm{C})$ WT-TAP became localized to the Golgi apparatus within 60 min (Fig. 3B, panels $\mathrm{d}-\mathrm{i}$ ). ATF6 $\alpha(\mathrm{C}) \mathrm{C} 467 \& 618 \mathrm{~A}-\mathrm{TAP}$ also became localized to the Golgi apparatus in response to dithiothreitol treatment (Fig. 3B, panels $\mathrm{m}-\mathrm{r}$ ). Immunoprecipitation of TAP-tagged ATF6 luminal domain with anti-c-myc epitope antibody followed by immunoblotting analysis with anti-KDEL antibody revealed that the ER chaperone BiP constitutively bound to TAP-tagged ATF6 luminal domain was dissociated from ATF6 $\alpha(\mathrm{C}) \mathrm{WT}-\mathrm{TAP}$ and ATF $6 \alpha(\mathrm{C}) \mathrm{C} 467 \& 618 \mathrm{~A}$ -
TAP similarly after dithiothreitol treatment (Fig. 3C), as in the case of endogenous ATF6 $\alpha$.

On treatment with thapsigargin, which is known to activate ATF6 weakly (Haze et al., 1999), levels of monomer and dimer 1 of ATF $6 \alpha(\mathrm{C}) \mathrm{WT}-\mathrm{TAP}$ were decreased (Fig. $4 \mathrm{~A}$, lanes $8-13)$, and ATF $6 \alpha(\mathrm{C}) \mathrm{WT}-\mathrm{TAP}$ became localized to the Golgi apparatus (Fig. 4B, panels $\mathrm{d}-\mathrm{i}$ ), albeit much more slowly than with dithiothreitol treatment. ATF $6 \alpha(\mathrm{C})$ C467\&618A-TAP also became localized to the Golgi apparatus (Fig. 4B, panels $\mathrm{m}-\mathrm{r}$ ) in response to thapsigargin treatment. When the effect of thapsigargin treatment was examined over a shorter time course (Fig. 4C), the level of dimer 1 was gradually decreased (lanes 8-13), whereas that of dimer 2 (lanes 8-13) or that of total ATF $6 \alpha($ C)WT-TAP (lanes 1-7) remained relatively constant. These results indicate that dimer 1 , containing only one disulfide bond, is preferentially reduced in response to the addition of weak ATF6 activator. Thus, the behavior of ATF $6 \alpha(\mathrm{C}) \mathrm{WT}-\mathrm{TAP}$ in ER-stressed cells is similar to that of endogenous ATF6 $\alpha$. 
A
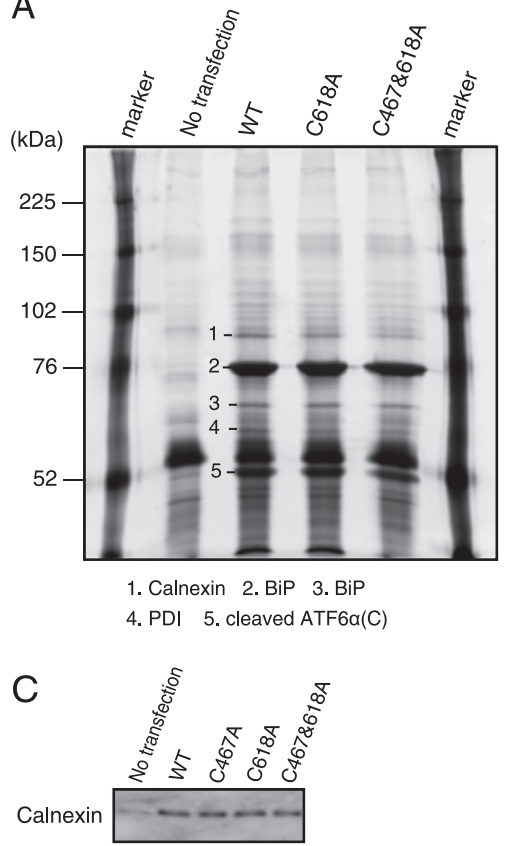

$\mathrm{BiP}$

PDI

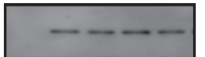

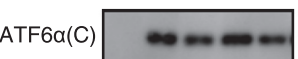

B
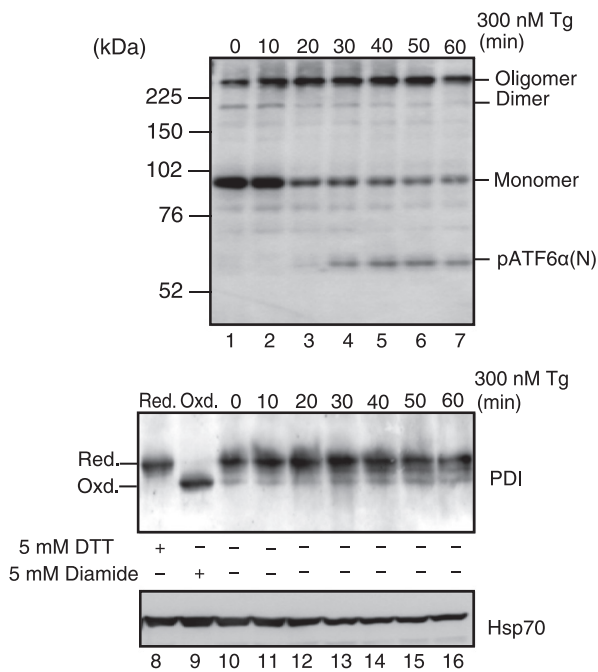

Fig. 6. Identification of proteins bound specifically to ATF6 $\alpha(C)$-TAP. HEK293 cells untransfected or transfected with a plasmid to express various forms of ATF $6 \alpha(\mathrm{C})$-TAP as indicated were lyzed and subjected to affinity chromatography using IgG sepharose as described in EXPEIMENTAL PROCEDURES. Bound proteins were eluted by digestion with TEV protease, subjected to SDS-PAGE under reducing condition, and visualized by silver staining. Mass spectrometric analysis revealed that three ER proteins (namely BiP, calnexin and PDI) were bound to ATF6 $\alpha(\mathrm{C})-\mathrm{TAP}$ specifically. (B) HEK293 cells were untreated or treated with $5 \mathrm{mM}$ dithiothreitol (DTT) for $5 \mathrm{~min}, 5 \mathrm{mM}$ diamide for $5 \mathrm{~min}$, or $300 \mathrm{nM}$ thapsigargin for the indicated periods. Cell lysates were prepared, subjected to SDS-PAGE under non-reducing conditions, and analyzed by immunoblotting using anti-ATF6 $\alpha$ antibody (upper panel). Cell lysates were also prepared and reacted with AMS as described in EXPERIMENTAL PROCEDURES, followed by immunoblotting analysis using anti-PDI or Hsp70 antibodies (lower panels). (C) The eluates from IgG sepharose prepared as in A were analyzed by immunoblotting using anti-calnexin, anti-KEDL and anti-PDI antibodies.

\section{Secretion of ATF6 luminal domain}

We noticed that total levels of ATF6 $\alpha(\mathrm{C}) \mathrm{WT}-\mathrm{TAP}$ and ATF6 $\alpha(C) C 467 \& 618 \mathrm{~A}-\mathrm{TAP}$ observed under reducing conditions were markedly decreased several hours after thapsigargin treatment (Fig. 4A, lanes 1-7 and 14-20). This observation suggested that these fusion proteins might be secreted after reaching the Golgi apparatus. To address this, the culture medium for $\mathrm{HeLa}$ cells expressing ATF $6 \alpha(\mathrm{C})$ WT-TAP or ATF6 $\alpha(\mathrm{C}) \mathrm{C} 467 \& 618 \mathrm{~A}-\mathrm{TAP}$ was changed to fresh medium with or without thapsigargin, and the cells were further incubated for $5 \mathrm{~h}$. Cells and medium at 0 and $5 \mathrm{~h}$ after the medium change were collected and subjected to immunoprecipitation using anti-c-myc epitope antibody, followed by immunoblotting analysis of the immunoprecipitated materials. In the absence of thapsigargin, both ATF $6 \alpha(\mathrm{C}) \mathrm{WT}-\mathrm{TAP}$ and ATF $6 \alpha(\mathrm{C}) \mathrm{C} 467 \& 618 \mathrm{~A}-$
TAP were detected in cell lysates but not in medium at both $0 \mathrm{~h}$ and $5 \mathrm{~h}$ (Fig. 5A, lanes 1-4 and 9-12). In contrast, in the presence of thapsigargin, both the ATF $6 \alpha(\mathrm{C}) \mathrm{WT}-\mathrm{TAP}$ and ATF6 $\alpha(C)$ C $467 \& 618 A-T A P$ detected in the cell lysates at $0 \mathrm{~h}$ nearly disappeared from cell lysates and were localized entirely to the medium at $5 \mathrm{~h}$ after the medium change (Fig. 5, lanes 5-8 and 13-16). The extracellular forms of ATF6 $\alpha(\mathrm{C})$ WT-TAP and ATF6 $\alpha(\mathrm{C}) \mathrm{C} 467 \& 618 \mathrm{~A}-\mathrm{TAP}$ obviously migrated more slowly than their intracellular forms (Fig. 5, compare lane 5 with lane 8 and lane 13 with lane 16).

The intracellular forms were sensitive to treatment with endoglycosidase $\mathrm{H}$ and protein- $\mathrm{N}$-glycosidase $\mathrm{F}$, as expected from their localization to the ER (Fig. 5, lanes 5-7 and 1517). In contrast, the extracellular forms were completely resistant to endoglycosydase $\mathrm{H}$ and partially resistant to protein-N-glycosidase F (Fig. 5, lanes 8-10 and 18-20). The extracellular forms appeared not to be phosphorylated, 
as they were resistant to treatment with bacterial alkaline phosphatase (data not shown). The observed partial resistance to protein-N-glycosidase $\mathrm{F}$ is likely explained by $\mathrm{O}$ glycosylation occurring in the Golgi apparatus (Shen et al., 2002). These results indicated that after ER stress-induced translocation to the Golgi apparatus, the carbohydrate moieties of ATF6 $\alpha(\mathrm{C}) \mathrm{WT}-\mathrm{TAP}$ and ATF6 $\alpha(\mathrm{C}) \mathrm{C} 467 \& 618 \mathrm{~A}-$ TAP were modified from high mannose-types to complex types and then they were secreted to medium.

\section{Isolation of ATF6 luminal domain-binding proteins}

Lastly, we examined whether or not ATF6 $\alpha(\mathrm{C}) \mathrm{WT}-\mathrm{TAP}$ can be used to isolate ATF6-binding proteins. HEK293 cells expressing ATF6 $\alpha(\mathrm{C}) \mathrm{WT}$-TAP were solubilized with $0.01 \%$ digitonin to remove cytosolic proteins. The pellets left behind were dissolved in 1\% digitonin, and the solubilized proteins were subjected to affinity chromatography using IgG sepharose. Bound proteins were eluted by digestion with TEV protease, subjected to SDS-PAGE under reducing conditions, and then silver-stained (Fig. 6A). Mass spectrometric analysis revealed that two ER proteins in addition to BiP were bound to ATF6 $\alpha(\mathrm{C}) \mathrm{WT}-\mathrm{TAP}$; calnexin and PDI. Calnexin very likely assists with productive folding of glycosylated ATF $6 \alpha(\mathrm{C}) \mathrm{WT}$-TAP.

To address the possibility that PDI is responsible for ER stress-induced reduction of ATF6, we used modification with AMS to determine whether or not the redox state of PDI was altered in response to ER stress. Only PDI with free cysteine residues (PDI contains a total of six) is modified by AMS, and this AMS-modified PDI migrates more slowly than unmodified PDI in SDS-PAGE. As a control, HEK293 cells were treated for $5 \mathrm{~min}$ with $5 \mathrm{mM}$ dithiothreitol or $5 \mathrm{mM}$ diamide for complete reduction or oxidation, respectively, and then cell lysates were incubated with AMS. PDI with all six cysteines modified by AMS (Fig. 6B, lane 8) migrated more slowly than PDI with no cysteines modified by AMS (Fig. 6B, lane 9) in SDS-PAGE. We further noted that most PDI in unstressed HEK293 cells existed in a reduced state (Fig. 6B, lane 10). After the addition of thapsigargin, the levels of monomer and dimer of endogenous ATF6 $\alpha$ were decreased from 20 min (Fig. 6B, lane 3$)$, and the cleaved form of ATF $6 \alpha, \operatorname{pATF} 6 \alpha(\mathrm{N})$, was detected from $30 \mathrm{~min}$ (Fig. 6B, lanes 4-7). However, the redox state of $P D I$ remained largely unchanged during the period (Fig. 6B, lanes 11-16), indicating that PDI is not responsible for the reduction of ATF6 in response to ER stress. This notion was further supported by subsequent purification experiments with $\operatorname{IgG}$ sepharose followed by elution with TEV protease, which showed that PDI bound not only to ATF6 $\alpha(\mathrm{C}) \mathrm{WT}-\mathrm{TAP}$ but also equally to ATF6 $\alpha(\mathrm{C}) \mathrm{C} 467 \mathrm{~A}-\mathrm{TAP}, \mathrm{ATF} 6 \alpha(\mathrm{C}) \mathrm{C} 618 \mathrm{~A}-\mathrm{TAP}$ and even to ATF6 $\alpha(\mathrm{C}) \mathrm{C} 467 \& 618 \mathrm{~A}-\mathrm{TAP}$ with no free cysteines, like calnexin and BiP (shown by silver staining in Fig. 6A and by immunoblotting in Fig. 6C). These results suggested that PDI bound to these TAP-tagged ATF6 luminal domains with chaperone activity regardless of the presence or absence of free cysteine residues.

\section{Discussion}

ATF6 is a transcription factor which acts in the regulation of ER quality control proteins and is required for transcriptional induction of ER chaperones and ERAD components in response to ER stress in mammals (Adachi et al., 2008). ATF6 senses ER stress via an unknown mechanism and subsequently relocates from the ER to the Golgi apparatus to be activated by regulated intramembrane proteolysis. Previous studies have shown that the luminal domain of ATF6 confers ER stress responsiveness to another ATF6-like ER membrane-bound transcription factor LZIP/Luman (Chen et al., 2002). Thus, a portion of LZIP (amino acids 1-280) consisting of its cytoplasmic and transmembrane regions as well as a short 31-amino acid region of its luminal domain were translocated to the Golgi apparatus in response to dithiothreitol treatment, but only when fused to the luminal domain of ATF6 (amino acids 430-670). This indicates that the ATF6 luminal domain is sufficiently able to sense ER stress and subsequently translocate to the Golgi apparatus (Chen et al., 2002). Here, we further found that the luminal domain of ATF6 alone fused to soluble TAP tag stays in the ER under normal growth conditions, and moves to the Golgi apparatus upon ER stress (Fig. 3 and Fig. 4), demonstrating that even transmembrane topology embedded in the ER is not required for the ER stress responsiveness of ATF6.

The best characterized ER membrane-bound transcription factors activated by regulated intramembrane proteolysis are sterol regulatory element-binding proteins 1 and 2 (SREBP-1 and SREBP-2) (Brown et al., 2000). SREBPs are synthesized as transmembrane proteins embedded in the ER with both their $\mathrm{N}$ - and C-terminals facing the cytoplasm, like a hairpin. When intracellular cholesterol levels are decreased, SREBPs are transported to the Golgi apparatus to be cleaved by sequential action of Site- 1 and Site- 2 proteases, the same enzymes as those which cleave ATF6. The N-terminal fragments of SREBPs liberated from the membrane translocate into the nucleus and activate transcription of genes involved in cholesterol homeostasis.

The anchor and escort proteins for SREBPs have been identified as Insig and SREBP cleavage-activating protein (SCAP), respectively, both of which span the ER membrane multiple times (DeBose-Boyd et al., 1999; Yang et al., 2002). Under normal conditions, the SREBP/SCAP complex is retained in the ER through binding of Insig to SCAP, to which cholesterol is directly bound. When cellular cholesterol level decreases, cholesterol detachment-induced conformational change of SCAP causes SCAP to dissociate from Insig, thereby allowing translocation of the SREBP/ SCAP complex to the Golgi apparatus (Brown et al., 2002; 
Radhakrishnan et al., 2004). In this regulatory mechanism, the escort protein SCAP associates with SREBP via direct interaction between the $\mathrm{C}$-terminal WD repeat domain of SCAP and the C-terminal regulatory domain of SREBP, with the interaction occurring in the cytoplasm (Sakai et al., 1997). Results from the present study suggest that a protein must recognize some point on the ATF6 luminal domain in order to escort ATF6 to the Golgi apparatus in response to ER stress. Thus, the nature of the putative ATF6 escort protein must differ substantially from the SREBP-escort protein SCAP.

ER stress-induced budding of ATF6 was recently reconstituted in vitro, in a study in which Chinese hamster ovary cells stably expressing ATF6 were first permeabilized with digitonin, and then mixed with GTP, rat liver cytosol, ATP, and an ATP regeneration system (Schindler and Schekman, 2009). Packaging of ATF6 into COPII vesicles was indeed enhanced on addition of the ER stress inducer dithiothreitol to the reaction or when Chinese hamster ovary cells stably expressing ATF6 were pretreated with dithiothreitol prior to permeabilization to prime ATF6 for transport. ATF6 was shown to be physically associated with COPII coat proteins such as Sec23 and Sec24, which were recruited to COPII vesicles through binding to the GTP-bound form of Sar1. Importantly, ATF6 packaging required no cytosolic component other than COPII. Taken together, these present and previous results suggest the possibility that an escort protein for ATF6 does indeed bind to the luminal domain of ATF6 in the ER and to Sec23/Sec24 in the cytosol at the same time.

The luminal domain of ATF6 alone fused to the TAP tag, ATF $6 \alpha(C)$ WT-TAP, behaved with marked similarity to the full-length ATF6. After synthesis on the ER membranebound ribosome, ATF $6 \alpha(\mathrm{C}) \mathrm{WT}$-TAP entered the ER lumen due to the presence of a signal peptide attached to the N-terminus, glycosylated (Fig. 5), and disulfide-bonded between two conserved cysteine residues (Fig. 1 and Fig. 2). Interestingly, ATF $6 \alpha(\mathrm{C}) \mathrm{WT}-\mathrm{TAP}$ was not stable and was degraded by the proteasome, giving rise to a half-life of approximately $2 \mathrm{~h}$, a value comparable to the short half-life of the full-length ATF6 $\alpha$ (Fig. 2D). On application of ER stress, the disulfide bond is reduced and the ER chaperone $\mathrm{BiP}$ is released, allowing translocation of ATF $6 \alpha(\mathrm{C}) \mathrm{WT}$ TAP to the Golgi apparatus (Fig. 3 and Fig. 4). These similarities encouraged us to isolate ATF6-binding protein from HEK293 cells expressing ATF6 $\alpha(C)$ WT-TAP by affinity chromatography using IgG sepharose. As a result, we identified the ER chaperones, calnexin, BiP, and PDI, as proteins capable of binding to ATF $6 \alpha(\mathrm{C}) \mathrm{WT}$-TAP specifically over no transfection control, which are considered to assist productive folding of ATF $6 \alpha(\mathrm{C}) \mathrm{WT}$-TAP (Fig. 6).

Taken together, our present results strongly suggest that the luminal domain of ATF6 fused to the TAP tag is a useful tool for isolating the oxidoreductases involved in ER stress-induced reduction of ATF6 luminal domain as well as any anchor or escort proteins involved in ER stress-induced relocation of ATF6 from the ER to the Golgi apparatus. Identification of such proteins will facilitate a more precise understanding of how ATF6 senses ER stress, and of how cells recognize the accumulation of unfolded proteins in the ER and initiate signaling to maintain ER homeostasis.

Acknowledgment. We thank Ms. Kaoru Miyagawa and Ms. Yayoi Yamamoto for their technical and secretarial assistance. We are grateful to Dr. Kikuchi for providing us anti-PDI antibody. This work was financially supported in part by grants from the Ministry of Education, Culture, Sports, Science and Technology of Japan (20247026 to K. M.) and also in part by the Global Center of Excellence Program, "Formation of a Strategic Base for Biodiversity and Evolutionary Research: from Genome to Ecosystem", of the Ministry of Education, Culture, Sports, Science and Technology of Japan.

\section{References}

Adachi, Y., Yamamoto, K., Okada, T., Yoshida, H., Harada, A., and Mori, K. 2008. ATF6 is a Transcription Factor Specializing in the Regulation of Quality Control Proteins in the Endoplasmic Reticulum. Cell Struct. Funct., 33: 75-89.

Brown, A.J., Sun, L., Feramisco, J.D., Brown, M.S., and Goldstein, J.L. 2002. Cholesterol addition to ER membranes alters conformation of SCAP, the SREBP escort protein that regulates cholesterol metabolism. Mol. Cell, 10: 237-245.

Brown, M.S., Ye, J., Rawson, R.B., and Goldstein, J.L. 2000. Regulated intramembrane proteolysis: a control mechanism conserved from bacteria to humans. Cell, 100: 391-398.

Chen, X., Shen, J., and Prywes, R. 2002. The luminal domain of ATF6 senses endoplasmic reticulum (ER) stress and causes translocation of ATF6 from the ER to the Golgi. J. Biol. Chem., 277: 13045-13052.

DeBose-Boyd, R.A., Brown, M.S., Li, W.P., Nohturfft, A., Goldstein, J.L., and Espenshade, P.J. 1999. Transport-dependent proteolysis of SREBP: relocation of site-1 protease from Golgi to ER obviates the need for SREBP transport to Golgi. Cell, 99: 703-712.

Haze, K., Yoshida, H., Yanagi, H., Yura, T., and Mori, K. 1999. Mammalian transcription factor ATF6 is synthesized as a transmembrane protein and activated by proteolysis in response to endoplasmic reticulum stress. Mol. Biol. Cell, 10: 3787-3799.

Haze, K., Okada, T., Yoshida, H., Yanagi, H., Yura, T., Negishi, M., and Mori, K. 2001. Identification of the G13 (cAMP-response-elementbinding protein-related protein) gene product related to activating transcription factor 6 as a transcriptional activator of the mammalian unfolded protein response. Biochem. J., 355: 19-28.

Jensen, O.N., Podtelejnikov, A., and Mann, M. 1996. Delayed extraction improves specificity in database searches by matrix-assisted laser desorption/ionization peptide maps. Rapid Commun. Mass Spectrom., 10: $1371-1378$

Mori, K. 2000. Tripartite management of unfolded proteins in the endoplasmic reticulum. Cell, 101: 451-454.

Nadanaka, S., Yoshida, H., Kano, F., Murata, M., and Mori, K. 2004. Activation of mammalian unfolded protein response is compatible with the quality control system operating in the endoplasmic reticulum. Mol. Biol. Cell, 15: 2537-2548.

Nadanaka, S., Yoshida, H., and Mori, K. 2006. Reduction of disulfide bridges in the lumenal domain of ATF6 in response to glucose starvation. Cell Struct. Funct., 31: 127-134.

Nadanaka, S., Okada, T., Yoshida, H., and Mori, K. 2007. A role of disulfide bridges formed in the lumenal domain of ATF6 in sensing endoplasmic reticulum stress. Mol. Cell. Biol., 27: 1027-1043.

Okada, T., Yoshida, H., Akazawa, R., Negishi, M., and Mori, K. 2002. 
Distinct roles of activating transcription factor 6 (ATF6) and doublestranded RNA-activated protein kinase-like endoplasmic reticulum kinase (PERK) in transcription during the mammalian unfolded protein response. Biochem. J., 366: 585-594.

Okada, T., Haze, K., Nadanaka, S., Yoshida, H., Seidah, N.G., Hirano, Y., Sato, R., Negishi, M., and Mori, K. 2003. A serine protease inhibitor prevents endoplasmic reticulum stress-induced cleavage but not transport of the membrane-bound transcription factor ATF6. J. Biol. Chem., 278: 31024-31032.

Radhakrishnan, A., Sun, L.P., Kwon, H.J., Brown, M.S., and Goldstein, J.L. 2004. Direct binding of cholesterol to the purified membrane region of SCAP: mechanism for a sterol-sensing domain. Mol. Cell, 15: 259268.

Ron, D. and Walter, P. 2007. Signal integration in the endoplasmic reticulum unfolded protein response. Nat. Rev. Mol. Cell Biol., 8: 519-529.

Rutkowski, D.T., Wu, J., Back, S.H., Callaghan, M.U., Ferris, S.P., Iqbal, J., Clark, R., Miao, H., Hassler, J.R., Fornek, J., Katze, M.G., Hussain, M.M., Song, B., Swathirajan, J., Wang, J., Yau, G.D., and Kaufman, R.J. 2008. UPR Pathways Combine to Prevent Hepatic Steatosis Caused by ER Stress-Mediated Suppression of Transcriptional Master Regulators. Dev. Cell, 15: 829-840.

Sakai, J., Nohturfft, A., Cheng, D., Ho, Y.K., Brown, M.S., and Goldstein, J.L. 1997. Identification of complexes between the COOH-terminal domains of sterol regulatory element-binding proteins (SREBPs) and SREBP cleavage-activating protein. J. Biol. Chem., 272: 20213-20221.

Sambrook, J., Fritsch, E.F., and Maniatis, T. 1989. Molecular Cloning: A Laboratory Manual. Cold Spring Harbor Laboratory Press, Cold Spring Harbor, New York.

Schindler, A.J. and R. Schekman. 2009. In vitro reconstitution of ER-stress induced ATF6 transport in COPII vesicles. Proc. Natl. Acad. Sci. USA, 106: $17775-17780$.

Shen, J., Chen, X., Hendershot, K., and Prywes, R. 2002. ER stress regulation of ATF6 localization by dissociation of BiP/GRP78 binding and unmasking of Golgi localization signals. Dev. Cell, 3: 99-111.

Wu, J., Rutkowski, D.T., Dubois, M., Swathirajan, J., Saunders, T., Wang, J., Song, B., Yau, G.D., and Kaufman, R.J. 2007. ATF6alpha optimizes long-term endoplasmic reticulum function to protect cells from chronic stress. Dev. Cell, 13: 351-364.

Yamamoto, K., Yoshida, H., Kokame, K., Kaufman, R.J., and Mori, K. 2004. Differential contributions of ATF6 and XBP1 to the activation of endoplasmic reticulum stress-responsive cis-acting elements ERSE, UPRE and ERSE-II. J. Biochem. (Tokyo), 136: 343-350.
Yamamoto, K., Sato, T., Matsui, T., Sato, M., Okada, T., Yoshida, H., Harada, A., and Mori, K. 2007. Transcriptional induction of mammalian ER quality control proteins is mediated by single or combined action of ATF6 $\alpha$ and XBP1. Dev. Cell, 13: 365-376.

Yamamoto, K., Suzuki, N., Wada, T., Okada, T., Yoshida, H., Kaufman, R.J., and Mori, K. 2008. Human HRD1 promoter carries a functional unfolded protein response element to which XBP1 but not ATF6 directly binds. J. Biochem. (Tokyo), 144: 477-486.

Yamamoto, K., Takahara, K., Oyadomari, S., Okada, T., Sato, T., Harada, A., and Mori, K. 2010. Induction of Liver Steatosis and Lipid Droplet Formation in ATF6 $\alpha$-knockout Mice Burdened with Pharmacological Endoplasmic Reticulum Stress. Mol. Biol. Cell, 21: 2975-2986.

Yang, T., Espenshade, P.J., Wright, M.E., Yabe, D., Gong, Y., Aebersold, R., Goldstein, J.L., and Brown, M.S. 2002. Crucial step in cholesterol homeostasis: sterols promote binding of SCAP to INSIG-1, a membrane protein that facilitates retention of SREBPs in ER. Cell, 110: 489-500.

Ye, J., Rawson, R.B., Komuro, R., Chen, X., Dave, U.P., Prywes, R., Brown, M.S., and Goldstein, J.L. 2000. ER stress induces cleavage of membrane-bound ATF6 by the same proteases that process SREBPs. Mol. Cell, 6: 1355-1364.

Yoshida, H., Haze, K., Yanagi, H., Yura, T., and Mori, K. 1998. Identification of the cis-acting endoplasmic reticulum stress response element responsible for transcriptional induction of mammalian glucoseregulated proteins; involvement of basic-leucine zipper transcription factors. J. Biol. Chem., 273: 33741-33749.

Yoshida, H., Okada, T., Haze, K., Yanagi, H., Yura, T., and Mori, K. 2000. ATF6 activated by proteolysis directly binds in the presence of NF-Y (CBF) to the cis-acting element responsible for the mammalian unfolded protein response. Mol. Cell. Biol., 20: 6755-6767.

Yoshida, H., Matsui, T., Yamamoto, A., Okada, T., and Mori, K. 2001 a. XBP1 mRNA is induced by ATF6 and spliced by IRE1 in response to ER stress to produce a highly active transcription factor. Cell, 107: 881891.

Yoshida, H., Okada, T., Haze, K., Yanagi, H., Yura, T., Negishi, M., and Mori, K. 2001b. Endoplasmic reticulum stress-induced formation of transcription factor complex ERSF including NF-Y (CBF) and activating transcription factors $6 \alpha$ and $6 \beta$ that activates the mammalian unfolded protein response. Mol. Cell. Biol., 21: 1239-1248.

(Received for publication, July 27, 2010, accepted, November 28, 2010 and publication online, December 8, 2010) 